\title{
Field resistance of Spodoptera litura (lepidoptera : noctuidae) to newer chemistry insecticide indoxicarb in Vidarbha
}

\author{
G.S. JEUGHALE*AND S.K. BHALKARE \\ Department of Entomology, Dr. Panjabrao Deshmukh Krishi Vidyapeeth, AKOLA (M.S.) INDIA
}

\section{ARITCLE INFO}

Received : 26.12 .2014

Accepted : 16.03 .2015

\section{KEY WORDS :}

Tobacco leaf eating caterpillar, Indoxicarb, Resistance monitoring

*Corresponding author:

Email: ipmgirish@yahoo.com

\begin{abstract}
The present studies were carried out to evaluate resistance in the population of Spodoptera litura Fab. (Lepidoptera, Noctuidae) from eight districts of Vidarbha region in India to indoxicarb from 2011-2013 using standard leaf dip bioassay method. For indoxicarb, resistance ratio compared with a susceptible strain were in range of 2.66 to 6.14 fold. However, relatively low level of resistance to indoxicarb was observed in all eight populations.
\end{abstract}

How to view point the article : Jeughale, G.S. and Bhalkare, S.K. (2015). Field resistance of Spodoptera litura (lepidoptera : noctuidae) to newer chemistry insecticide indoxicarb in Vidarbha. Internat. J. Plant Protec., 8(1) : 194-198. 